\title{
ELEMENTOS DA TEORIA DO PRECEDENTE JUDICIAL
}

\section{ELEMENTS OF THE THEORY OF JUDICIAL PRECEDENT}

\author{
Luís Henrique Barbante FRANZÉ ${ }^{1}$ \\ Giovane Moraes PORTO ${ }^{2}$
}

Artigo recebido em: 08/05/2016

Artigo aprovado em: 29/08/2016

RESUMO: A presente pesquisa pretende analisar os principais elementos da teoria do precedente judicial. Tendo como principal referêncial a Teoria formulada por Thomas de Bustamante. Assim, o objetivo desta pesquisa é apresentar os principais elementos do instituto dos precedentes judiciais, principalmente, quanto à atribuição de racionalidade ao sistema e a vinculação desta racionalidade a casos futuros. Verificar-se-á no que consiste a ratio decidendi, obter dictum, distinguish, overruling, debate entre a teoria declaratória e a teoria constitutiva ou posistivista do direito, diferença entre o instituto do precedente, jurisprudência e súmulas vinculantes. A metodologia utilizada será de caráter hipotético-dedutivo a partir de pesquisa bibliográfica. É esperado chamar atenção dos juristas para os elementos deste instituto como forma de aprimorar o ordenamento jurídico e a construção do direito por meio dos discursos racionais das decisões judiciais.

PALAVRAS-CHAVES: Teoria do Precedente Judicial; Racionalidade Jurídica; Decisão Judicial.

\footnotetext{
${ }^{1}$ Pós-Doutor em Direito pela Faculdade de Direito da Universidade de Lisboa. Doutor em Processo Civil pela PUC-SP. Mestre em Direito pela Faculdade de Direito de Bauru. Professor no programa de mestrado da Fundação de Ensino Eurípedes Soares da Rocha em Marília (UNIVEM) e no programa de graduação da Universidade Metodista de Piracicaba (UNIMEP). Vice-Lider do Grupo de Pesquisa Constitucionalização do Direito Processual (CODIP). Advogado. E-mail: Inbfranze@gmail.com

${ }^{2}$ Graduando em Direito pelo Centro Universitário Eurípides de Marília - UNIVEM. Bolsista PIBIC/CNPq sob orientação do Prof. Dr. Nelson Finotti Silva. Integrante e monitor do grupo de pesquisa Constitucionalização do Direito Processual (CODIP), vinculado ao CNPq-UNIVEM. E-mail: giovanemoraesporto@hotmail.com
} 
ABSTRACT: This research aims to analyze the main elements of the theory of judicial precedent. Having as main referential the theory formulated by Thomas Bustamante. The objective of this research is to introduce the main elements of the judicial precedents institute primarily on the attribution of rationality to the system and linking this rationality from case to case. Will be verified, as is the ratio decidendi, obter dictum, Distinguish, Overruling, discussions between the declaratory theory and constitutive theory or positivist theory of law, the difference between the precedent institute, jurisprudence and binding precedents. The methodology used is hypothetical-deductive from literature. It is expected to draw attention of lawyers for the elements of this institute as a way to improve the legal system and the construction of law through rational discourse of judgments.

KEYWORDS: Theory of Judicial Precedent; Legal Rationality; Judicial Decision 


\section{Introdução}

O tema foi escolhido, porque um dos grandes obstáculos da ciência jurídica é a busca por mecanismos de aperfeiçoamento do sistema jurídico a fim de melhor regulamentar a vida em sociedade e tornar possível o convívio, portanto, cada vez mais, há a comunicação entre as tradições jurídicas a fim de aperfeiçoar cada uma e o instituto dos precedentes judiciais vem sendo analisados e tentando ser implementados nos países da civil law.

Apresentar-se-á os principais elementos da teoria do precedente judicial como maneira de esclarecer no que consiste estes elementos, com o objetivo de analisar métodos de construção do direito por meio do conhecimento produzido com base em uma racionalidade em uma decisão judicial, ou seja, auferir uma arque-genealogia deste instituto jurídico.

Assim, em um primeiro momento, este estudo examinará no que consiste a ratio decidendi e o obter dictum, a fim de verificar o elemento vinculante da decisão judicial e suas implicações na interpretação e aplicação da forma jurídica. Após, serão verificadas os métodos de não aplicação do precedente - distinguish e overruling. Tendo como principal referencial a teoria do precedente formulada por Thomas de Bustamante.

Ao final, será possível distinguir o instituto do precedente com o da jurisprudência e das súmulas vinculantes, verificando que cada instituto possui suas peculiaridades e o uso como sinônimos desvirtua a finalidade de um ou de ambos os institutos.

No mais, esta pesquisa não tem a pretensão de esgotar o tema, mas apenas de trazer informações que instiguem o debate, notadamente, sobre a atribuição de racionalidade ao sistema jurídico por meio de um conhecimento construído na decisão judicial.

A metodologia utilizada foi de caráter dedutivo utilizando a pesquisa bibliográfica como fonte de observação teórica, principalmente no que concerne às construções teóricas de Thomas da Rosa de Bustamante e da teoria crítica do direito, a fim de analisar o instituto dos precedentes judicias conforme os pressupostos da teoria geral do Direito.

\section{Do precedente judicial}

Os precedentes judiciais são decisões judiciais que devem ser utiliza- 
das em casos futuros como parâmetro para a solução, caso não seja este o caso torna-se mera decisão judicial anterior, uma vez que a decisão não é um precedente, mas torna-se um por meio de sua utilização como paradigma. Este "uso" como paradigma se dá por meio da ratio decidendi que é o elemento vinculante do decisum.

Como ressalta Lenio Luiz Streck (2013, p. 42-43):

O precedente é uma decisão de um Tribunal com aptidão a ser reproduzida-seguida pelos tribunais inferiores, entretanto, sua condição de precedente dependerá de ele ser efetivamente seguido na resolução de casos análogos-similares. Ou seja, não há uma distinção estrutural entre uma decisão isolada e as demais que lhe devem "obediência hermenêutica". Há, sim, uma diferença qualitativa, que sempre exsurgirá a partir da applicattio.

O próprio conceito de precedente não é pacífico na doutrina. Por exemplo, para Thomas da Rosa de Bustamante (2007, p. 300-301) consiste em qualquer decisão judicial prévia que um juiz se embasa para fundamentar o seu pronunciamento sobre um caso atual. Entretanto para Luiz Guilherme Marinoni (2013, p. 214) consiste na decisão judicial que elabora uma tese jurídica. Após trazer conceito parecido, Caio Márcio Gutterres Taranto (2010, p. 8) acrescenta que o precedente tem a função de atribuir racionalidade.

Portanto, para a presente pesquisa, o precedente será considerado como a decisão prévia que produz uma norma, por meio de uma tese jurídica, com a finalidade de atribuir racionalidade ao sistema, que poderá ser utilizada como paradigma para futuras decisões.

O Direito não deve ser apenas aplicado, mas também justificado de forma racional, conforme as teorias positivistas pós-hartiana e a concepção hermenêutica do linguistic turn. As Constituições contemporâneas, em sua maioria, exigem que todas as decisões sejam fundamentadas, sob pena de nulidade - princípio da motivação das decisões judiciais - para impedir que haja decisões arbitrárias como as proferidas no período inquisitivo e no Antigo Regime ${ }^{3}$.

Com o sistema dos precedentes tal fundamentação da decisão poderá

\footnotetext{
${ }^{3}$ Como salienta Thomas da Rosa de Bustamante: O Direito deve ser compreendido como uma prática social de natureza hermenêutica, pois a concretização de seus comandos depende sempre de uma atividade de interpretação (em sentido amplo) - que é a um só tempo um processo de conhecimento e de construção de sentido - dos enunciados normativos (que constituem, obviamente, enunciados linguísticos) por meio dos quais ele se expressa. (BUSTAMANTE, 2012, p. 126).
} 
ser utilizada como paradigma em casos futuros, uniformizando o entendimento, e restringindo o poder discricionário do juiz. Este instituto não engessa o significado atribuído aos textos normativos, mas os constrói a cada caso de forma discurso-argumentativa.

Como salienta Lenio Luiz Streck (2013, p. 96):

O precedente dinamiza o sistema jurídico, não o engessa, isto porque a interpretação do precedente tem que levar em conta a totalidade do ordenamento jurídico e toda a valoração e a fundamentação que o embasaram, assim, sempre que ele for a base de uma nova decisão, seu conteúdo é passível de um ajuste jurisprudencial, nesse sentido, Keith Eddey ressalta as vantagens do sistema de precedentes como sua dinamicidade para se encontrar a resposta adequada à solução jurídica.

No presente texto iremos analisar os principais elementos da teoria dos precedentes judiciais, principalmente sobre a ratio decidendi - elemento vinculante do precedente - e as técnicas de não aplicação do decisum.

\section{Ratio decidendi e obter dictum}

Os principais elementos da teoria dos precedentes judiciais consistem nas técnicas de não aplicação do precedente (distinguish e overruling) e na técnica de vinculação do decisum (ratio decidendi e obter dictum). Há, também, a discussão sobre a formação do direito, momento de sua criação, debate entre a teoria declaratória e a teoria constitutiva ou positivista.

Os precedentes judiciais são muitas vezes confundidos com outros institutos jurídicos. Iremos analisar a diferença entre os precedentes e a jurisprudência e entre os precedentes e as súmulas vinculantes, porquanto, são estes os dois institutos que mais se assemelham ao precedente.

Para verificarmos as técnicas de não aplicação do precedente - distinguish e overruling - é necessária a análise de seu elemento vinculante, portanto iremos analisar, primeiramente, no que consiste a ratio decidendi ${ }^{4}$.

\footnotetext{
${ }_{4}^{4}$ Tal como salienta Gustavo Santana Nogueira: Dizer que um precedente vincula, na verdade, é dizer pouco. Um precedente pode ter páginas e mais páginas e muito pouco do seu conteúdo pode vincular os julgadores em casos futuros. Só se pode falar em adesão aos precedentes a partir do momento em que se separam duas partes fundamentais de uma decisão judicial: a ratio decidendi (literalmente, razões de decidir) e a obter dictum (literalmente, dito para morrer) (NOGUEIRA, p. 182).
} 
Nesse contexto, a ratio decidendi vai ser um fragmento da decisão que irá servir de parâmetro para o julgador em casos futuros, analisar se os casos se assemelham, os motivos determinantes para a decisão e, se for o caso, superar o argumento anterior, isto é, superar a norma anterior ${ }^{5}$.

Para localizar a ratio decidendi em uma decisão judicial é necessário reconstruir subsuntivamente/silogisticamente a justificação racional, para verificar a relação entre as suas premissas e o resultado do julgamento. A fim de verificar quais são os argumentos que sem eles não seria possível chegar naquele resultado do julgamento ${ }^{6}$.

Deste modo, o elemento da decisão que não influiu no resultado do julgamento é chamado de obter dictum e não vinculará os demais julgamentos. Já a parte da decisão que foi decisiva para o resultado do julgamento será a ratio decidendi. Portanto, é possível a presença de mais de um argumento que interfira no resultado do julgamento, podendo conter rationes decidendis. "A dificuldade para determinar a ratio decidendi de um caso qualquer decorre, em minha opinião, da pressuposição de que há apenas uma ratio em cada caso julgado" (BUSTAMANTE, 2012, p. 270). Entre as rationes decidendi pode haver diferentes graus de vinculação, a chamada "força gravitacional"7 pode variar entre as rationes ${ }^{8}$.

Portanto, a análise da ratio decidendi é muito importante para a teoria jurídica, pois é o elemento que irá construir o direito de forma racional, construir

${ }^{5}$ Este é o posicionamento de Estefânia Maria de Queiroz Barboza, ao expressar: Para que uma opinião tenha o peso de um precedente é necessário que ela tenha sido dada por um juiz e também que tenha sido necessária para a decisão de um caso particular, isto é, não pode ser obiter dictum. A ratio decidendi de uma decisão nos sistemas de common law é o que vai criar um precedente vinculante nas decisões seguintes e, portanto, se faz necessário descobri-la (BARBOZA, 2014, p. 217).

\footnotetext{
${ }^{6}$ Thomas da Rosa de Bustamante entende que: "Tal reconstrução pressupõe, antes de tudo, uma ferramenta analítica para elucidar a estrutura das decisões judiciais e revelar todas as premissas normativas contidas em sua fundamentação. Tal ferramenta analítica pode ser a enunciação formal dessas premissas normativas sob a forma de silogismos práticos, isto é, silogismos "cuja premissa maior e cuja conclusão não são enunciados que se assume exprimirem proposições apofânticas, mas enunciados que se assume exprimirem proposições prescritivas" [Chiassoni 1999:152] (BUSTAMANTE, 2012, p. 278).
}

${ }^{7}$ Sobre a "força gravitacional do precedente judicial" ver Bustamante, 2012, p. 302.

\footnotetext{
${ }^{8}$ Este é o entendimento de Thomas da Rosa de Bustamante, ao expressar: Precedentes judiciais são, como enunciados legislativos, textos dotados de autoridade que carecem de interpretação. É trabalho do aplicador do Direito extrair a ratio decidendi - o elemento vinculante - do caso a ser utilizado como paradigma. Mas a noção de ratio decidendi e os critérios para sua determinação contituem algo ainda fortemente controvertido. Talvez este seja o ponto mais polêmico da teoria dos precedentes e de toda a teoria jurídica produzida no common law (BUSTAMANTE, 2012, p. 259).
} 
o entendimento jurisprudencial, impor o conhecimento a ser seguido. A fim de gerar coerência, previsibilidade, integridade, segurança e estabilidade.

No entanto, conforme aponta Marcelo Alves Dias de Souza (2013, p. 125-133), existem algumas teorias sobre o que deve ser analisado para localizar a ratio decidendi da decisão: Pela teoria de Eugene Wambaugh (conhecida como teoria clássica), a "ratio decidendi" será a proposição necessária para uma decisão; Pela teoria de Herman Oliphant, a "ratio decidendi" serão os fatos existentes nos autos que estimularam a resposta do tribunal, devendo ser ignorado o trabalho mental usado, na decisão, pelo juiz; Pela teoria de Arthur Goodhart, a "ratio decidendi" consiste nos fatos que o juiz considerou como fundamentais ("material facts") para a sua decisão. Assim, o primeiro passo seria a identificação dos fatos jurídicos relevantes e, a partir daí, se passa ao desenvolvimento das regras para esta busca.

O problema da teoria de Herman Oliphant é que se mostra ilógica esta separação entre o trabalho mental do juiz e os fatos que estimularam a conclusão. Não há como julgar um caso apenas com base nos fatos, ignorando todo um raciocínio que imputará um texto normativo ao caso concreto. $\mathrm{O}$ mesmo problema está na teoria de Wambaugh, pois desconsidera os fatos, analisa apenas a regra jurídica.

A teoria de Arthur Goodhart - que, grosso modo, procura aprimorar a teoria de Eugene Wambaugh -, a ratio decidendi pode ser conceituada como os fatos considerados pelo pronunciamento (antecedentes) que conduziram efetivamente ao resultado da decisão (consequente) ${ }^{9}$. Portanto a ratio decidendi estaria tanto nas questões fáticas quanto nas questões jurídicas, seria este raciocínio do julgador em imputar um texto normativo aos fatos do caso, enquadrar os fatos jurídicos na moldura do texto normativo.

Portanto, entre as formas de localizar a ratio decidendi em uma decisão, há discussão sobre se deve buscar as razões de decidir nos fatos jurídicos (Oliphant), nas prescrições normativas (Wambaugh), ou a terceira hipótese que soma as duas anteriores, buscar na relação entre os fatos e as prescrições normativas (Goodhart). Prevalece, atualmente, que a ratio decidendi deve ser buscada na relação entre o fato e as prescrições normativas. Pois, é ilógico pensar

\footnotetext{
9 Embora os limites desta pesquisa impedem o aprofundamento sobre estas teorias, vale registrar que Arthur Goodhart (1930, p. 167) chegou a argumentar que poderiam existir decisões em que a "ratio decidendi" não estaria nos fundamentos.
} 
que o julgador irá decidir só com base nos fatos, ou só com base no direito ${ }^{10}$.

O precedente deve estar sempre ligado ao caso que lhe deu origem, não podendo se desligar, pois a ratio decidendi deve ser buscada nos argumentos fundamentais para o resultado do julgamento, portanto o que irá servir de fonte do direito, de poder vinculativo, são os argumentos, a construção de saber, a imposição de significado ao texto normativo que produz a norma, que sempre estará ligado às questões de fato e de direito ${ }^{11}$.

A partir da ratio decidendi é possível verificar a racionalidade utilizada para justificar a decisão judicial, para impor um saber como verdadeiro e construir um conhecimento acerca do significado do texto normativo, que deverá ser seguido nas futuras decisões, excluindo os conhecimentos contrários, hierarquizar a força de cada argumento, de cada ratio decidendi e, por fim, controlar a construção do direito, controlar a fonte do direito.

Por seu turno, a obter dictum - o elemento não vinculante de um precedente judicial - é verificada na justificação da decisão por exclusão, ou seja, aqueles argumentos que não são considerados ratio decidendi, não influenciam o resultado do julgamento ${ }^{12}$, são considerados obter dictum, por isso "dito para morrer"13.

Além disso, para a teoria dos precedentes judiciais, é possível, por

\footnotetext{
${ }^{10}$ Esta forma de reconstrução do precedente é bem exposta por Thomas da Rosa de Bustamante, ao expressar: propomo-nos a reconstruir os argumentos das decisões judiciais dessa forma - e passamos a contemplar a decisão judicial não como uma única regra, mas como uma cadeia de razões -, podemos visualizar as decisões judiciais não como um silogismo, mas como uma série de silogismos onde, por exemplo, o enunciado que está na conclusão de um raciocínio interpretativo sobre uma norma (um silogismo interpretativo) é ao mesmo tempo a premissa maior de um silogismo em que os fatos relevantes para a justificação da decisão final formam a premissa menor (BUSTAMANTE, 2012, p. 282).
}

${ }^{11}$ Daí porque deve ser observada a ponderação de Lenio Luiz Streck, ao afirmar que: A partir dessas diversas concepções de ratio decidendi, é possível dizer que, tradicionalmente, ela configura o enunciado jurídico a partir da qual é decidido o caso concreto. Em suma, ela é a regra jurídica utilizada pelo Judiciário para justificar a decisão do caso. Todavia, ela não é uma regra jurídica que pode ser considerada por si só, ou seja, se ela for encarada isoladamente, ela deixará de ser ratio decidendi, uma vez que a ratio decidendi deve, obrigatoriamente, ser analisada em correspondência com a questão fático-jurídica (caso concreto) que ela solucionou (STRECK, 2013, p. 43).

${ }^{12}$ Como salienta "o obter dictum corresponde ao enunciado, interpretação jurídica, ou uma argumentação ou fragmento de argumentação jurídica, expressamente contidos na decisão judicial, cujo conteúdo e presença são irrelevantes para a solução final da demanda" (STRECK, 2013, p. 44).

${ }^{13}$ O uso do critério da exclusão para conceituar a "obter dictum" é trazido por Thomas da Rosa de Bustamante, ao expressar: De modo geral, o conceito de dictum é definido per exclusionem: todas as normas e afirmações que não puderem ser enquadradas no conceito estrito de ratio decidendi têm sua autoridade descartada e valem apenas pela força de convencimento que eventualmente possam vir a ter [Marshall 1997:515; Taruffo 1994:420] (BUSTAMANTE, 2012, p. 276). 
meio da ratio decidendi, determinar se o caso em discussão e o anterior são semelhantes. Portanto a técnica de não aplicação do precedente - o distinguish depende diretamente da extração da ratio decidendi ${ }^{14}$.

\section{Distinguish e overruling}

$\mathrm{O}$ distinguish consiste em não aplicar um precedente por afirmar que o caso em análise não é semelhante ao caso do precedente. A ratio decidendi é muito importante para não caírem em um "distinguish radical" ao afirmar que "cada caso é um caso"15.

A técnica de não aplicação do precedente pelo fato dos casos não serem semelhantes - distinguish - fica a cargo do julgador, que terá de decidir se se aplica determinada norma, determinado raciocínio jurídico ou se não aplica devido a não semelhança, fática e jurídica, entre os casos. Porém, não é possível a afirmação de que cada caso é um caso ou, o oposto, que os casos devem ser idênticos. Esta verificação de semelhança ou não se dá por meio da ratio decidendi.

Outra técnica de não aplicação dos precedentes é a do overruling, que consiste no ato do julgador dizer que a ratio decidendi do precedente está ultrapassada, que aquele entendimento deve ser superado, o conhecimento produzido não configura mais uma verdade, não deve mais ser seguido, deve ser superado, a fim de impor um novo conhecimento, uma nova regra a ser seguida ${ }^{16}$.

$\mathrm{O}$ overruling consiste na troca da regra de direito, na troca da ratio decidendi, por considerar ultrapassada, impondo uma nova regra a ser seguida. $\mathrm{O}$ sistema jurídico não deve ser somente estático, deve ter o caráter dinâmico, também, para acompanhar as mudanças da sociedade, para melhor

\footnotetext{
${ }^{14}$ Ressalta Gustavo Santana Nogueira, que: "Na técnica do distinguishing valoriza-se sobremaneira a ratio decidendi do precedente, além de procurar dar a essa ratio o seu verdadeiro alcance" (NOGUEIRA, p. 213).

${ }^{15}$ Ressalta Gustavo Santana Nogueira, que: "Todos os casos submetidos ao Judiciário contém diferenças entre si, posto que se forem idênticos estaremos diante do fenômeno da duplicidade de ações (litispendência), porém os casos, quando postos em comparação, podem conter semelhanças que justifiquem a aplicação ao caso que está sendo julgado da ratio decidendi do precedente. Não há uma fórmula que identifique com precisão que tipo de diferenças podem justificar a não aplicação do precedente, cabendo a cada juiz fazer a sua análise e ao Tribunal que elaborou o precedente verificar, quando cabível, se o distinguishing foi corretamente feito (NOGUEIRA, p. 213).

${ }^{16}$ Ressalta Gustavo Santana Nogueira, que: Através dessa técnica o Tribunal supera o precedente. Fazer o overruling significa que o Tribunal claramente sinaliza o fim da aplicação de uma regra de direito estabelecida pelo precedente e substitui a velha regra de direito por uma que é fundamentalmente de natureza diversa (NOGUEIRA, p. 193).
} 
regulamentar, controlar a conduta de cada indivíduo, não deixando o direito ultrapassado às condutas humanas, à realidade social ${ }^{17}$.

Tanto a teoria estática do direito, como a teoria dinâmica do direito, são reguladas pelo Estado, ou seja, independente da fonte do direito, o Estado, por meio do direito, é que se auto regulará, a formação das prescrições normativas para a forma jurídica é sempre regulada pela própria forma jurídica, há um monopólio, por parte do Estado, na formação do direito, consequentemente, no controle sobre a conduta de cada indivíduo, na imposição e criação de um modo de agir em sociedade, a fim de concretizar os interesses do Estado ${ }^{18}$.

Portanto, por mais que considere o precedente como fonte do direito, a produção da norma como vinculante para a decisão do caso futuro, isto não atribui à sociedade o poder de criar o direito, de se auto regulamentar, o direito será sempre uma imposição com base na noção jurídica de soberania. O próprio direito pode se auto regulamentar, e se desenvolver a cada decisão, mas o poder para a técnica do overruling sempre será do Estado.

Ocorre que esta mudança de entendimento não pode se dar ao bel prazer dos julgadores, só é possível esta mudança se houver algum motivo relevante para isto, alguma mudança no sistema jurídico, político, social, econômico ou cultural. Pois, se não fosse assim não haveria uniformização do entendimento, os julgadores poderiam mudar o entendimento sobre determinado assunto sempre que quisessem ${ }^{19}$.

\footnotetext{
${ }^{17}$ Sobre o tema Hans Kelsen, salienta que: É, com efeito, uma característica muito significativa do Direito o fato de ele regular a sua própria produção e aplicação. A produção das normas jurídicas gerais, isto é, o processo legislativo, é regulado pela Constituição, e as leis formais ou processuais, por sua vez, tomam à sua conta regular a aplicação das leis materiais pelos tribunais e autoridades administrativas. Por isso, os atos de produção e de aplicação (que, como veremos, também é ela própria produção) do Direito, que representam o processo jurídico, comente interessam ao conhecimento jurídico enquanto formam o conteúdo de normas jurídicas, enquanto são determinados por normas jurídicas. Desta forma, também a teoria dinâmica do Direito é dirigida a normas jurídicas, a saber, àquelas normas que regulam a produção e a aplicação do Direito (KELSEN, 1991, p. 78).

${ }^{18}$ Sobre o tema Hans Kelsen, salienta que: Conforme a ênfase é dada a um ou a outro elemento desta alternativa: as normas reguladoras da conduta humana ou a conduta humana regulada pelas normas; conforme $o$ conhecimento é dirigido às normas jurídicas produzidas, a aplicar ou a observar por atos de conduta humana ou atos de produção, aplicação ou observância determinados por normas jurídicas, podemos distinguir uma teoria estática e uma teoria dinâmica do Direito. A primeira tem por objetivo o Direito como um sistema de normas em vigor, o Direito no seu momento estático; a outra tem por objeto o processo jurídico em que o Direito é produzido e aplicado, o Direito no seu movimento (KELSEN, 1991, p. 78).

${ }^{19}$ Ressalta Gustavo Santana Nogueira, que: O Direito não é imutável, precisa ser estável mas não imutável. As decisões judiciais, a partir de um determinado momento, precisam ser protegidas com o manto da imutabilidade (coisa julgada) para proporcionarem segurança jurídica às partes que se envolveram naquele litígio, mas o Direito está sempre em processo de evolução. O que hoje é juridicamente aceito, amanhã pode não o ser mais, de modo que o Direito, como produto da sociedade destinado à sociedade, precisa se adaptar às mudanças que a sociedade exige (NOGUEIRA, p. 201).
} 
Para os súditos não ficarem a mercê das mudanças do entendimento sobre o significado dos textos normativos há o instituto da coisa julgada, que não permite a alteração na decisão, salvo algumas exceções legais que permitem a flexibilização deste instituto, mas isto é de acordo com o ordenamento de cada território o que não será objeto de análise do presente texto devido ao corte metodológico de análise.

A análise do overruling e do distinguish possuem implicações fundamentais na análise da relação dos precedentes judiciais com a teoria declaratória e com a teoria constitutiva ou positivista do direito, uma vez que o precedente é considerado fonte do direito faz necessário saber qual o poder do juiz ao utilizar desta fonte e qual a genealogia da legitimação da utilização uma decisão como paradigma para a solução de um caso concreto.

\section{Teoria declaratória e teoria constitutiva ou positivista}

Os precedentes, apesar de configurarem fontes do direito, não estão acima da lei. Estão limitados ao quadro normativo imposto pelo legislativo, por isto é uma forma de limitação à discricionariedade. Porém, mesmo com a discricionariedade limitada há o reconhecimento, a criação, do direito. Sempre haverá margem para a discricionariedade, se fosse possível extinguir toda a discricionariedade poderiam substituir os julgadores por computadores ${ }^{20}$.

O debate entre a teoria declaratória e a teoria constitutiva ou positivista é muito importante para a teoria jurídica, a fim de analisar a genealogia do direito. A teoria declaratória entende que o direito preexiste à decisão judicial, esta apenas reconhece e atribui o dever de obediência, limitada às prescrições legislativas.

Ao passo que, a teoria constitutiva ou positivista, entende que a decisão judicial que determina a proveniência do direito, o direito não preexiste, só será considerado direito a partir da decisão judicial.

Nas duas teorias há a vinculação da decisão judicial, há a subordinação ao conhecimento produzido pela decisão, à imposição de significado ao texto

\footnotetext{
20 Ressalta Gustavo Santana Nogueira, que: Os precedentes não se situam acima da lei, mas são apenas interpretações dessa lei. É claro que existe a discussão entre as teorias declaratórias e constitutivas acerca da possibilidade do juiz criar o direito, mas de qualquer forma, ainda que ele possa, por decisão judicial, criar o direito, estará ele obviamente submisso à vontade do legislador se o "direito criado judicialmente" foi legislativo por quem de direito (NOGUEIRA, p. 200).
} 
normativo e o dever de observância ${ }^{21}$.

Ficando evidente que, a partir da adoção da teoria jurídica positivista pós-hartiana e do linguistic turn, a teoria que prevalece é a teoria constitutiva ou positivista do direito. Pois, apesar do precedente estar limitado ao quadro normativo, este não possui significado por si, necessita de um discurso racional feito por meio de uma decisão judicial para atribuir significado ao texto normativo, ou seja, para "preencher" o quadro. Portanto, o julgador não apenas declara algo que já existia, ele constitui, cria, o direito, mesmo que tendo a discricionariedade limitada por esta moldura. O que preexiste é a moldura a ser preenchida, não o direito propriamente dito.

O direito é uma ciência social, a lei jurídica determina o que vai acontecer por meio de uma imputação, ao contrário das ciências naturais onde as leis naturais determinam o que vai acontecer por meio de uma relação causal (princípio da causalidade), relação de causa e efeito. Portanto, o direito é contranatural, é uma invenção, um produto do homem, um produto da sociedade, que se aplica por meio do princípio da imputação ${ }^{22}$.

Sendo assim, quem detém o monopólio de criação do direito - como vimos, é o Estado - detém o poder de controlar e disciplinar a vida em sociedade e imputar as consequências, ou seja, a utilização de mecanismos disciplinares, de cada um que age de forma contrária à determinada pela forma jurídica, conforme lembra Hans Kelsen, ao expressar:

A forma verbal em que são apresentados tanto o princípio da causalidade como o da imputação é um juízo hipotético em que um determinado pressuposto é ligado com uma determinada consequência. O sentido da ligação, porém, é - como já vimos - diferente nos dois casos. O princípio da causalidade afirma

\footnotetext{
${ }^{21}$ Esta forma de reconstrução do precedente é bem exposta por Thomas da Rosa de Bustamante, ao expressar: Da teoria positivista podemos extrair a afirmação - geralmente correta - de que os juízes têm determinado poder criativo ao interpretar e aplicar o Direito aos casos concretos; da teoria declaratória podemos derivar a tese de que, em um importante sentido, os juízes, quando aplicam o Direito a determinado caso concreto, estão vinculados pelo conteúdo das prescrições normativas que podem de modo geral ser derivadas do Direito e de sua sistematização racional (BUSTAMANTE, 2012, p. 264-265).

${ }^{22}$ Sobre o tema Hans Kelsen, salienta que: Determinando o Direito como norma (ou, mais exatamente, como um sistema de normas, como uma ordem normativa) e limitando a ciência jurídica ao conhecimento e descrição de normas jurídicas e às relações, por estas constituídas, entre fatos que as mesmas normas determinam, delimita-se o Direito em face da natureza e a ciência jurídica, como ciência normativa, em face de todas as outras ciências que visam o conhecimento, informado pela lei da causalidade, de processos reais. Somente por esta via se alcança um critério seguro que nos permitirá distinguir univocamente a sociedade da natureza e a ciência social da ciência natural.(KELSEN, 1991, p. 84).
} 
que, quando A, B também é (ou será). O princípio da imputação afirma que, quando A é, B deve ser. (KELSEN, 1991, p. 100).

A consequência prevista no direito não se aplica por uma relação de causa e efeito, não é porque um indivíduo cometeu um ilícito que ele irá sofrer as consequências, ele deverá sofrer as consequências e para que isto ocorra necessita de um julgador para imputar a ele a consequência do ilícito. Sendo esta a distinção feita por Kelsen sobre o princípio da causalidade e o princípio da imputação, consequentemente, o que difere as ciências sociais das ciências naturais.

Portanto, o controle da conduta não é automático, natural, relação de causalidade, mas é imputado por alguém, precisa do julgador para concretizar esta imputação, e para que isto ocorra o julgador utiliza da racionalidade para fundamentar sua decisão e legitimar a consequência prevista na forma jurídica.

A partir dos elementos que estudamos da teoria do precedente judicial, passar-se-á a analisar a diferença do precedente com outros dois institutos que são corriqueiramente confundidos, o instituto da "jurisprudência" e o instituto brasileiro das "súmulas vinculante".

\section{Diferenças entre precedente, jurisprudência e súmulas vinculantes}

O precedente não deve ser confundido com jurisprudência. Há duas distinções principais entre estes dois institutos, uma diferença qualitativa e uma diferença quantitativa. A utilização destes institutos como sinônimos pode desvirtuar a finalidade de um, ou de ambos, os institutos.

A diferença qualitativa é quanto à racionalidade da decisão, a imposição do significado, a construção do saber. O precedente possui mais qualidade do que a jurisprudência, pois o importante no precedente é a justificação da decisão, o saber construído em sua fundamentação, ao passo que o que interessa na jurisprudência são as decisões reiteradas que adotam o mesmo entendimento, portanto, o que é importante não é a justificação, a ratio decidendi, cada argumento utilizado, mas a conclusão, a parte dispositiva ${ }^{23}$.

${ }^{23}$ Como salienta Lenio Luiz Streck: O precedente pode ser constituído apenas a partir de uma decisão que lhe seja subjacente (e.g., Marbury vs. Madison). Outrossim, o precedente fornece regra jurídica universalizável que passa a ser utilizada como critério de decisão. A jurisprudência, por sua vez, necessita de série reiterada de decisões para ser caracterizada, e a análise da questão fática dos casos que ela solucionará é menos rigorosa e precisa que a aplicação do precedente (STRECK, 2013, p. 93). 
Por sua vez, a diferença quantitativa é quanto ao número de julgamentos que cada instituto está ligado. A jurisprudência é mais quantitativa que o precedente. Pelo fato de a jurisprudência ser decisões reiteradas, necessita pelo menos de duas decisões para configurar o "reiteradas". Ao passo que, o precedente sempre estará ligado ao caso que lhe deu origem, ao caso concreto, sempre a este caso e nenhum outro. O precedente sempre estará relacionado com apenas um caso, nunca mais do que isto. A jurisprudência nunca poderá ser de apenas um caso, como ressalva Michelle Taruffo, ao expressar:

Há, antes de tudo, uma distinção de caráter - por assim dizer quantitativo. Quando se fala do precedente, faz-se geralmente referência a uma decisão relativa a um caso particular, enquanto quando se fala da jurisprudência faz-se, normalmente, referência a uma pluralidade frequentemente muito ampla de decisões relativas a vários e diversos casos concretos (TARUFFO, 2014, p. 3).

Portanto, as duas principais diferenças entre o precedente e a jurisprudência são de caráter qualitativo e quantitativo. Estes institutos não comportam uma relação de gênero e espécie, de hierarquia, como se todo precedente se tornaria jurisprudência ou vice e versa. São institutos autônomos, apesar dos dois poderem ser visto como fontes do direito.

O instituto do precedente judicial é muito confundido, no Brasil, com o instituto das súmulas vinculantes. Assim como a jurisprudência, estes dois institutos decorrem do poder judiciário e vinculam as futuras decisões. Porém para fazer uma diferenciação mais precisa é necessário verificar qual elemento da súmula vinculante que vincula.

A doutrina não é pacífica quanto ao elemento vinculante das súmulas, uns entendem que é só o enunciado da súmula, outros entendem que é o enunciado juntamente com os casos que deram origem à súmula, pois todas as súmulas precisam ser baseadas, derivadas, de casos concretos.

Os que entendem que o elemento vinculante das súmulas é só o enunciado argumentam que "súmula não é precedente stricto sensu, por várias razões. Talvez a principal delas seja porque o texto é diferente de norma. Não deveria haver uma confusão entre as funções de criar um texto e de concretizar uma norma" (STRECK, 2013, p. 52). Portanto, as súmulas seriam mero texto sem significado, ao passo que o precedente seria a decisão que atribui significado ao texto. 
Para compreendermos a distinção para esta corrente precisamos retomar a diferença entre texto e norma. As súmulas seriam texto, por serem abstratas e não estarem ligadas a nenhum caso concreto, o precedente, ao contrário, seria a norma, por estar ligado, diretamente, a um caso concreto. $\mathrm{O}$ precedente seria detentor de sentido, a súmula não ${ }^{24}$.

Outra diferença entre súmula e precedente é que a súmula é feita para a solução de casos futuros, casos que estão por vir, ou seja, de antemão quer prever a solução de casos que virão a acontecer, enquanto que o precedente é feito para solucionar um caso concreto passado e sua utilização para a solução de casos futuros é meramente incidental. Esta diferença é comum às duas teorias ${ }^{25}$.

A teoria que entende que a parte vinculante da súmula vinculante é o enunciado (texto), juntamente com os casos que deram origem a súmula, entende não ser possível diferenciar os institutos afirmando que o precedente está ligado a um caso concreto em quanto as súmulas não, pois entendem que as súmulas não se desligam dos casos que lhe deram origem.

Sendo assim, apesar da súmula ser diferente do precedente pelo fato que aquela visa a solução de casos futuros e este visa a solução de um único caso passado, é possível a utilização de alguns elementos da teoria do precedente judicial no instituto das súmulas. Principalmente, as técnicas da ratio decidendi e obter dictum, do overruling e do distinguish ${ }^{26}$.

A extração da ratio decidendi não estaria no enunciado da súmula, mas nos casos concretos que deram origem às súmulas, assim como a técnica do distinguish consistiria na diferenciação do caso a ser solucionado com os casos que deram origem à súmula. A técnica do overruling consiste no fato de superar o(s) argumento(s) utilizado(s) para a solução dos casos que deram origem à súmula.

\footnotetext{
${ }^{24}$ Como salienta Lenio Luiz Streck: A súmula vinculante, por sua vez, da mesma forma que o assento português, desvincula-se do(s) caso(s) que a originaram, ela se impõe como um texto normativo de vinculação geral e abstrata para casos futuros tal qual a lei, possui dimensão atemporal, logo, duração indefinida, passando a ter validade após sua publicação na imprensa oficial (STRECK, 2013, p. 63).

${ }^{25}$ Como salienta Marcelo Alves Dias de Souza: No que diz respeito à SV, surge o questionamento acerca do que efetivamente vincula: se tão-só o enunciado sumular ou também as decisões tomadas anteriormente. Considerando-se que o enunciado sumular apenas cristaliza o entendimento do Supremo acerca de determinada matéria, servindo de elemento que tende a pacificar divergências e uniformizar a atuação do próprio Poder Judiciário e da Administração Pública direta e indireta, infere-se que não apenas o enunciado sumular, mas todas as decisões anteriores são vinculantes (SOUZA; COL, 2011, p. 81).

${ }^{26}$ Sobre o tema, Marcelo Alves Dias de Souza salienta que: Nesse sentido, verifica-se que a SV possui grande similitude com os binding precedents no sistema da common law, pois, como estes, cria norma, extraível da ratio decidendi; e, igualmente, pode a súmula vinculante ser revista (como o distinguishing daquele sistema) ou cancelada (de modo semelhante ao overruling) (SOUZA; COL, 2011, p. 79).
} 


\section{Considerações finais}

O precedente judicial tem por finalidade atribuir racionalidade ao sistema por meio de um conhecimento produzido em uma tese jurídica, com o escopo de construir o direito de forma dinâmica, por via da decisão judicial.

A ratio decidendi é o elemento vinculante da decisão que servirá de paradigma para a solução de casos futuros e por meio desta é possível a extração do que consiste o obter dictum e a aplicação dos métodos de não aplicação - distinguish e overruling.

A construção do Direito por meio das decisões judiciais atribui coerência, estabilidade, dinamicidade, segurança e integridade. $\mathrm{O}$ instituto do precedente possui características próprias, portanto, se distingue dos outros institutos, o uso de institutos diversos como sinônimos implica no desvirtuamento da finalidade, pois cada instituto jurídico possui um telos que deve ser estabelecido pela diálogo intersubjetivo na práxis jurídica respeitando as regras do discurso, mas se a utilização do instituto não estiver de acordo com o estabelecido democraticamente pelo diálogo intersubjetivo o aplicador estará violando até mesmo o Estado Democrático de Direito e as consequências podem ser prejudiciais aos jurisdicionados, já que o instituto não está coerente com a teoria que o sustenta e legitima.

\section{Referências}

BARBOZA, Estefânia Maria de Queiroz. Precedentes judiciais e segurança jurídica: fundamentos e possibilidades para a jurisdição constitucional brasileira. São Paulo: Saraiva, 2014.

. Escrevendo um romance por meio dos precedentes judiciais: uma possibilidade de segurança jurídica para a jurisdição constitucional brasileira. Revista de Direito Administrativo \& Constitucional I, Belo Horizonte, ano 14, n. 56, p. 177-207, abr/jun. 2014.

BUSTAMANTE, Thomas da Rosa de. Teoria do precedente judicial: a justificação e a aplicação de regras jurisprudenciais. São Paulo: Noeses, 2012. 
DAVID, René. Os grandes sistemas do direito contemporâneo. Traduzido por Hermínio A. Carvalho. São Paulo: Martins Fontes.

KELSEN, Hans. Teoria pura do direito. Tradução João Baptista Machado: revisão para a edição brasileira Silvana Vieira. 3. ed. São Paulo: Martins Fontes, 1991.

MARINONI, Luiz Guilherme. Precedentes obrigatórios. 3. ed. São Paulo: Revista dos Tribunais, 2013.

NOGUEIRA, Gustavo Santana. Precedentes vinculantes no direito comparado e brasileiro. 2 ed. Salvador: JusPodivm.

ROCHA, Mauro Sérgio. Aplicação direta de princípios constitucionais: justificação das decisões judiciais. In: Cunha, J. S. Fagundes (Org.). O Direito nos Tribunais Superiores: com ênfase no novo direito processual civil. Curitiba: Bonijuris, 2015.

SOUZA, Marcelo Alves Dias de. Do precedente judicial à súmula vinculante. Curitiba: Editora Juruá, 2013.

STRECK, Lenio Luiz. O que é isto - decido conforme minha consciência? 4. ed. Porto Alegre: Livraria do Advogado, 2013.

ABBOUD, Georges. O que é isto - o precedente judicial e as súmulas vinculantes. Porto Alegre: Livraria do Advogado, 2013.

TARANTO, Caio Márcio Gutterres. Precedente judicial: autoridade na jurisdição constitucional. Rio de Janeiro: Forense, 2010.

TARUFFO, Michele. Precedente e jurisprudência. Tradução: Chiara Antonia Spadaccini de Teffé. Civilistica a.3 n.2: Rio de Janeiro, 2014. 